\title{
Phylogeny of Opisthokonta and the evolution of multicellularity and complexity in Fungi and Metazoa
}

\author{
Mónica Medina',5*, Allen G. Collins ${ }^{2,3}$, John W. Taylor ${ }^{4}$, James W. Valentine ${ }^{3}$, \\ Jere H. Lipps ${ }^{3}$, Linda Amaral-Zettler' and Mitchell L. Sogin' \\ ${ }^{1}$ Josephine Bay Paul Center for Comparative Molecular Biology and Evolution, Marine Biological Laboratory, \\ 7 MBL Street, Woods Hole, MA 02543, USA \\ ${ }^{2} I T Z$, Ecology \& Evolution, Tierärztliche Hochschule Hannover, Bünteweg 17d, 30559 Hannover, Germany \\ ${ }^{3}$ Department of Integrative Biology and Museum of Paleontology, University of California, Berkeley, CA 94720, USA \\ ${ }^{4}$ Department of Plant and Microbial Biology, University of California, Berkeley, CA 94720, USA \\ ${ }^{5}$ DOE Joint Genome Institute, 2800 Mitchell Drive, Walnut Creek, CA 94598, USA
}

\begin{abstract}
While early eukaryotic life must have been unicellular, multicellular lifeforms evolved multiple times from protistan ancestors in diverse eukaryotic lineages. The origins of multicellularity are of special interest because they require evolutionary transitions towards increased levels of complexity. We have generated new sequence data from the nuclear large subunit ribosomal DNA gene (LSU rDNA) and the SSU rDNA gene of several unicellular opisthokont protists - a nucleariid amoeba (Nuclearia simplex) and four choanoflagellates (Codosiga gracilis, Choanoeca perplexa, Proterospongia choanojuncta and Stephanoeca diplocostata) to provide the basis for re-examining relationships among several unicellular lineages and their multicellular relatives (animals and fungi). Our data indicate that: (1) choanoflagellates are a monophyletic rather than a paraphyletic assemblage that independently gave rise to animals and fungi as suggested by some authors and (2) the nucleariid filose amoebae are the likely sister group to Fungi. We also review published information regarding the origin of multicellularity in the opisthokonts.
\end{abstract}

Received 1 April 2003, accepted 10 July 2003

Key words: Choanoflagellata, Fungi, Mesomycetozoea, Metazoa, multicellularity, Nuclearia, Opisthokonta.

\section{Introduction}

Transitions from unicellular to multicellular organisms surely are key events in the evolution of life on Earth, permitting divisions of labour that have led to sequential increases in developmental complexity. Molecular trees show that the transition of unicellular eukaryotes to multicellularity occurred multiple times in distinct lineages. These analyses also provide a framework for identifying and timing the evolutionary pathways and innovations that led to the origin of multicellular lineages and the subsequent generation of developmental complexity (Wainright et al. 1993; CavalierSmith 1998). Genomic techniques, increasingly, are clarifying the molecular bases of regulatory gene networks responsible for the cell differentiation and patterning, and that underlie increases in complexity. However, the genomic approach is inherently comparative, and only in combination with phylogenetics will it reach its full potential. To help provide a more robust phylogeny for the origins of multicellularity in the Opisthokonta, which includes the Metazoa, Fungi, Choanoflagellata, and Mesomycetozoea, we conducted a

\footnotetext{
* Corresponding author. Present address: Joint Genome Institute, 2800 Mitchell Drive, Walnut Creek, CA 94598, USA.

e-mail: m_medina@lbl.gov
}

phylogenetic analysis that includes new nuclear ribosomal gene sequences from a nucleariid amoeba and four species of choanoflagellates.

\section{Opisthokont diversity}

A variety of phylogenetic analyses based upon comparisons of different gene families show that fungi are specifically related to animals to the exclusion of green plants, alveolates, stramenopiles and many separate protist lineages (Baldauf \& Palmer 1993; Wainright et al. 1993). Furthermore, several protistan lineages may have diverged near the branch between animals and fungi. Most of these hypothesized relationships are based on nuclear small subunit ribosomal DNA (SSU rDNA) (Ragan et al. 1996; Atkins et al. 2000; Amaral-Zettler et al. 2001), but some are also based on protein coding sequences (King \& Carroll 2001; Snell et al. 2001; Lang et al. 2002) (see the discussion section). The clade that comprises metazoan, fungal and protistan taxa, and that is exclusive of other multicellular taxa (such as plants, and red and brown algae), is now known as Opisthokonta (CavalierSmith 1987, 1998). Two synapomorphies present in most of the opisthokont taxa are the presence of flat mitochondrial cristae and a posteriorly uniflagellate motile state (CavalierSmith 1987, 1998). 
Despite the common ancestry suggested by molecular data, the affinity of animals with a particular opistokhont clade has been elusive. Many distinct opistokhont lineages vary widely in life history, external morphology and ultrastructural characters. Within the Opisthokonta, the Fungi are the most diverse showing non-flagellate and flagellate forms (sometimes with zoospores that can move like amoebae (Sparrow 1960)), as well as unicellular and multicellular morphologies. The other key lineages within the Opisthokonta are the Mesomycetozoea (Mendoza et al. 2001), also known as the 'DRIPs' (Ragan et al. 1996), Icthyosporea (Cavalier-Smith 1998), and Mesomycetozoa (Herr et al. 1999). These are a group of mostly parasitic protists that infect diverse tissues in several animal hosts, including humans (reviewed in Mendoza et al. 2002). The Choanoflagellata are cosmopolitan free-living uniflagellate organisms that may be either solitary or colonial and they share many characters with sponges (see Nielsen 2001), and, by extension, to Metazoa. Corallochytrium limacisporum, a free-living but non-flagellate protist that inhabits tropical reef waters, resembles thrausochytrids (Labyrinthulomycota, Stramenopila), but is more closely related to choanoflagellates than to either Stramenopila, Fungi or Metazoa (Cavalier-Smith \& Allsopp 1996). Ministeria vibrans, another non-flagellate protist, falls within the Opisthokonta in phylogenetic trees based on SSU data (Cavalier-Smith 2000). Most recently, Amaral-Zettler et al. (2001) proposed that free-living filose nucleariid amoebae are members of Opisthokonta. These authors suggested that the members of this genus, Nuclearia, were not likely to be monophyletic, because a unicellular eukaryotic snail symbiont had been placed, provisionally, in the genus. However, this organism recently was reassigned to a new genus as Capsaspora owczarzaki (Hertel et al. 2002), and has been shown to be a member of the Mesomycetozoea by the use of longer ribosomal sequences (Hertel et al. 2002).

\section{Molecular markers}

Because morphological synapomorphies that unite the different unicellular and multicellular opisthokont lineages are difficult to identify, molecular characters, particularly SSU sequences and a growing dataset of full-length largesubunit ribosomal DNA (LSU) sequences, are used to infer opisthokont relationships. While SSU sequences have not provided sufficient resolution for the deeper divergences within Opisthokonta, the taxon sampling is by far the best available. Here we present new SSU evidence for four choanoflagellates (Codosiga gracilis, Choanoeca perplexa, Proterospongia choanojuncta and Stephanoeca diplocostata) and new LSU data for a nucleariid amoeba to test two different hypotheses concerning relationships between unicellular opisthokont protists and their multicellular counterparts: (1) Fungi and animals arose independently from two different choanoflagellate lineages rendering this taxonomic group paraphyletic (Cavalier-Smith 1987). Only a few choanoflagellate sequences were publicly available to rigorously test this hypothesis. In this paper we challenge this hypothesis with four new sequences from the three different choanoflagellate families: Acanthoecidae, Codonosigidae and Salpingoecidae (see Table 2 later). (2) Although the SSU data presented by Amaral-Zettler et al. (2001) suggested that the nucleariid amoebae are opisthokont taxa, their precise phylogenetic analysis left the placement of these taxa unresolved. Here we present LSU data from Nuclearia simplex in an attempt to improve our understanding of this important group of protists.

\section{Materials and methods}

\section{New sequences}

We extracted DNA from Nuclearia simplex (CCAP 1552/4) using the puregene isolation kit according to manufacturer's instructions. We used the primers F63m and 28S-amp developed by Medina et al. (2001) to amplify and sequence approximately four $\mathrm{kb}$ of the LSU rRNA gene. We performed DNA amplifications by long polymerase chain reaction (PCR) $\left(94{ }^{\circ} \mathrm{C} 5 \mathrm{~min}, 94{ }^{\circ} \mathrm{C} 30 \mathrm{~s}, 45^{\circ} \mathrm{C} 1 \mathrm{~min}, 65^{\circ} \mathrm{C}\right.$ $\left.12 \mathrm{~min} \times 30,72^{\circ} \mathrm{C} 10 \mathrm{~min}\right)$. The enzyme used was a combination of rTth (Perkin Elmer) and vent polymerases (NEB). After A-tailing with Taq polymerase, the PCR product was cloned into a TOPO vector (Invitrogen). A single clone was sequenced in both directions in a LiCor $4200 \mathrm{~L}$ apparatus (LiCor, Lincoln, Nebraska). For the combined analysis, we obtained the remaining SSU and LSU sequences from GenBank (Table 1). Choanoflagellate genomic DNA was isolated from frozen cell $\left(-80^{\circ} \mathrm{C}\right)$ samples of four species (Table 1) by pulverizing it in the reagent DNAzol (Chomczynski et al. 1997), followed by centrifugation and ethanol precipitation. We amplified the complete sequences for SSU using eukaryotic-specific primers (Medlin et al. $1988)$ via $\mathrm{PCR}\left(94{ }^{\circ} \mathrm{C} 2 \mathrm{~min}, 94^{\circ} \mathrm{C} 10 \mathrm{~s}, 38-48{ }^{\circ} \mathrm{C} 1 \mathrm{~min}\right.$, $72{ }^{\circ} \mathrm{C} 3 \mathrm{~min} \times 30$ ). PCR products were directly sequenced in both directions with an ABI Prism 377 DNA Sequencer (PerkinElmer Instruments, Norwalk, Connecticut).

\section{Phylogenetic analyses}

Alignments for both molecules were refined by eye using a multiple sequence alignment editor. We encoded secondary structure in the alignment, identifying stems, loops and bulges, and manually excluded regions of ambiguous alignment from the final dataset. The final alignment of both genes used in the combined analyses includes 3872 characters, 2317 from the LSU and 1555 SSU alignments, respectively. The final SSU alignment includes 1674 characters.

We performed nested likelihood ratio tests (LRT), using Modeltest version 3.0 (Posada \& Crandall 1998), in order to determine the model of sequence evolution for which the data were most likely. The LRT implemented in Modeltest 3.0 indicated that the model that best fitted the combined dataset was a $\operatorname{TrN}+\mathrm{I}+\Gamma$ (Tamura-Nei + invariants + gamma). The assumed proportion of invariable sites was 0.3369 , and the shape parameter (alpha) was 0.5681 . The best model chosen by Modeltest for the SSU dataset was GTR $+\mathrm{I}+\Gamma$ (general-time reversible + invariants + gamma). The assumed proportion of invariable sites was 0.2942 , and the shape parameter $(\alpha)$ was 0.6026 . 
Table 1. List of species used in the combined analysis, current taxonomic classification and accession numbers; new sequences are presented in bold

\begin{tabular}{|c|c|c|c|}
\hline & & SSU & LSU \\
\hline \multicolumn{4}{|l|}{ Outgroup taxa } \\
\hline Oryza sativa & Viridiplantae & $\mathrm{X} 00755$ & M11585 \\
\hline Funaria hygrometrica & Viridiplantae & X80212 & X99331 \\
\hline Prorocentrum micans & Alveolata, Dinophyceae & M14649 & X16108 \\
\hline Toxoplasma gondii & Alveolata, Apicomplexa & M97703 & X75430 \\
\hline Ochromonas danica & Stramenopile, Chrysophyceae & M32704 & Y07977 \\
\hline Skeletonema pseudocostatum & Stramenopile, Bacillariophyta & M54988 & Y11512 \\
\hline \multicolumn{4}{|l|}{ Opisthokont protists } \\
\hline Ichthyophonus hoferi & Mesomycetozoean & U25637 & AY026370 \\
\hline Monosiga brevicolis ATCC 50154 & Choanoflagellida & AF 100940 & AY026374 \\
\hline Salpingoeca infusionum ATCC 50559 & Choanoflagellida & AF100941 & AY026380 \\
\hline Nuclearia simplex CCAP (1552/4) & Nucleariidae & AF349566 & AY148095 \\
\hline \multicolumn{4}{|l|}{ Fungi } \\
\hline Candida albicans & Ascomycota & X53497 & X70659 \\
\hline Saccharomyces cerevisiae & Ascomycota & J01355 & M27607 \\
\hline Tricholoma matsutake & Basidiomycota & U62538 & U62964 \\
\hline Mucor racemosus & Zygomycota & AJ271061 & AJ271061 \\
\hline Blastocladiella emersonii & Chytridiomycota & M54937 & X90411 \\
\hline \multicolumn{4}{|l|}{ Animals } \\
\hline Mycale fibrexilis & Porifera & AF100946 & AY026376 \\
\hline Leucosolenia sp. & Porifera, Calcarea & AF100945 & AY026372 \\
\hline Antipathes galapagensis & Cnidaria & AF100943 & AY026365 \\
\hline Hydra circumcincta & Cnidaria & AF358080 & AY026371 \\
\hline Pleurobrachia bachei & Ctenophora & AF293677 & AY026378 \\
\hline Beroe ovata & Ctenophora & AF293694 & AY026369 \\
\hline
\end{tabular}

We used PAUP* 4.0 (Swofford 2000) for most phylogenetic analyses. We conducted maximum-likelihood (ML), minimum-evolution (ME) and maximum-parsimony (MP) searches. For ME and MP, we performed heuristic searches, with 1000 replicates of random stepwise addition and TBR branch swapping. For ML, we performed heuristic searches, with five replicates of random stepwise addition and TBR branch swapping. To estimate branch support we performed 100 bootstrap pseudoreplicates for ML (only combined data) and 1000 pseudoreplicates for ME and MP.

Additionally, we produced Bayesian phylogenetic inference trees using MrBayes 2.0 (Huelsenbeck \& Ronquist 2001). We performed exploratory Markov chain Monte Carlo (MCMC) runs, starting with random trees and a GTR $+\mathrm{I}+\Gamma$ (general-time reversible + invariants + gamma) model of evolution. Subsequently, we ran the heated MCMC chain for 500000 generations, which was sampled every 10 updates. We discarded 10000 cycles as burn-in before estimating joint posterior probabilities. We submitted data matrices and resulting trees to the TreeBase database under submission number SN1520.

\section{Results}

\section{Relationships among major groups}

Fig. 1 shows the optimal ML phylogenetic tree using a combined data set of SSU and LSU sequences while Fig. 2 (also see Table 2) is a comparable analysis for only the SSU sequences. Both trees show support values for nodes according to several different phylogenetic methods.
Overall, our analyses offer strong support for the monophyly of the opisthokonts but at the same time describe independent animal and fungal clades. In both trees, mesomycetozoeans and choanoflagellates form the sister group to animals, but support for this potential relationship is low. The status of Nuclearia as the sister group to Fungi is well supported in the combined analysis, while in the SSU analysis the Nuclearia taxa are basal to the animal/ choanoflagellate/mesomycetozoean group, all of which are sister to Fungi, but support is lacking. The relationship between mesomycetozoeans and choanoflagellates will require further exploration. Our data suggest that these two lineages form a monophyletic group but with weak bootstrap support. Additionally, the placement of Corallochytrium and Ministeria, remains uncertain, in part because of the lack of an LSU sequence. Our SSU analysis with many more choanoflagellate and mesomycetozoean species also suggests that extant choanoflagellates are monophyletic.

\section{Relationships within groups}

The combined analyses support the monophyly of the Choanoflagellata, although this phylogenetic inference did not include an acanthoecid choanoflagellate. Sampling of SSU sequences from choanoflagellate species is still sparse, but our additional sequences permit some observations concerning relations within the crown group. Acanthocoepsis, Diaphanoeca and Stephanoeca form a robustly supported clade (Fig. 2). We found the SSU sequences of Proterosponga choanojuncta and Choanoeca perplexa to be identical. 


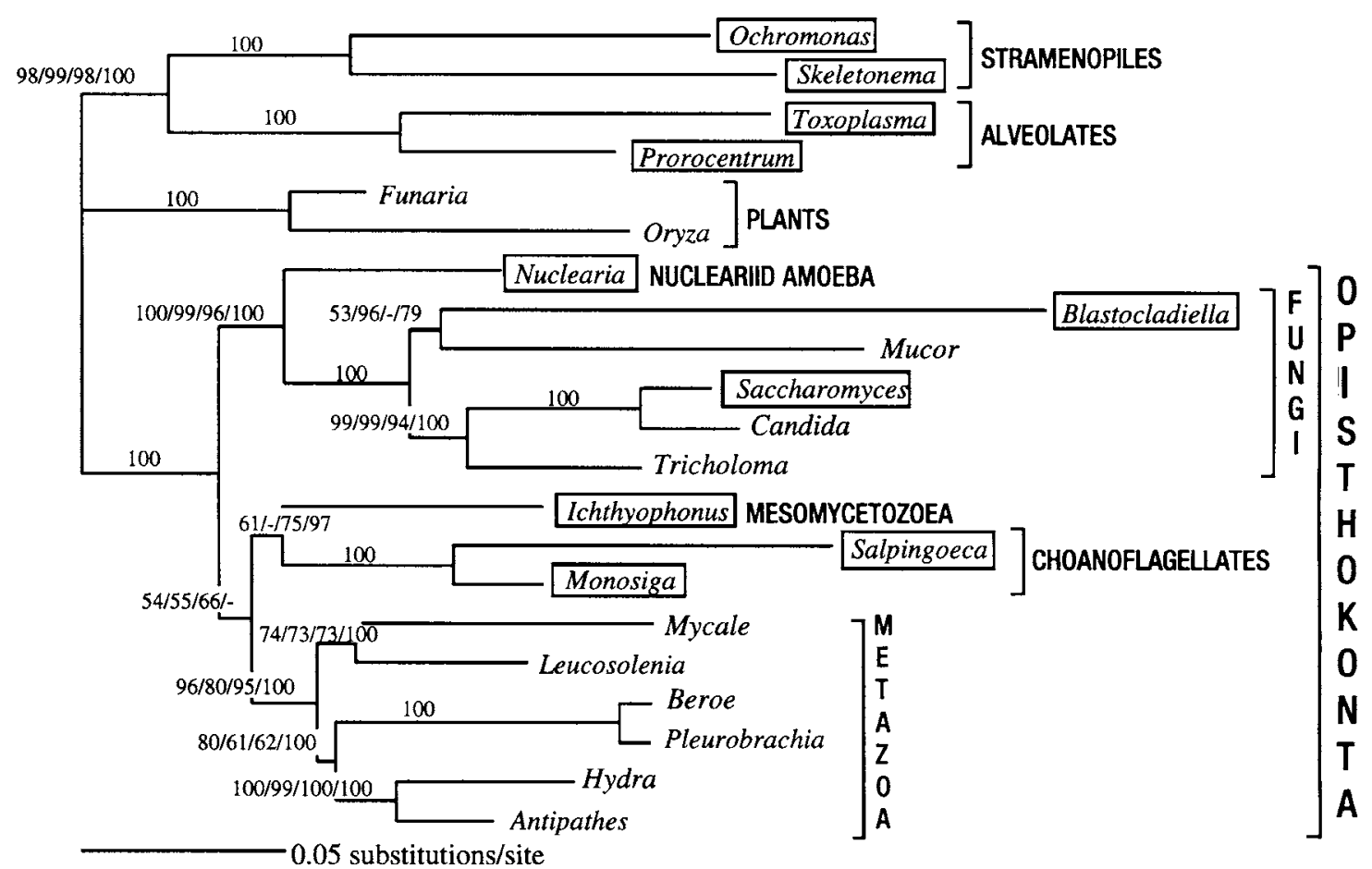

Fig. 1. Opisthokont phylogenetic analysis of SSU plus LSU rDNA. Best tree obtained by ML. The first three values above branches correspond to bootstrap values for ML, MP and ME, respectively. The fourth value corresponds to posterior probabilities from the Bayesian analysis (a single value of 100 indicates same support in all analyses). Unicellular organisms are boxed. The evolutionary distance is represented by the scale bar. See Table 1 for complete species name. The Nuclearia simplex strain sequenced in this study is actually the same as the strain labelled N. s.WB in Hertel et al. (2002) (correction made by that author as a personal communication). The $N$. simplex strain, CCAP (1552/4), sequenced in this study is the Heidelberg strain.

Members of the newly identified Mesomycetozoea protistan group was divided into two distinct monophyletic orders, based on SSU data and life history traits (Mendoza et al. 2002). Our SSU analysis (Fig. 2) also recovers the same two groups with high support.

The monophyly of Fungi is well supported by all methods of assessing support in the combined analysis and by the Bayesian posterior probabilities in the SSU analysis. Both the SSU and combined analyses support the Ascomycota/ Basydiomycota sister group relationship, as well as their monophyly (Fig. 2). Although our SSU data do not resolve the basal fungal relationships, our results are congruent with other phylogenetic analyses (Nagahama et al. 1995; James et al. 2000), which showed that the earliest diverging fungal clades were lineages of Chytridiomycota and Zygomycota, and that neither group was monophyletic.

The monophyly of Metazoa is also well supported by our analyses and the branching pattern in this part of the trees is in agreement with published ribosomal phylogenies for this group (Collins 1998; Medina et al. 2001).

\section{Discussion}

\section{Choanoflagellate hypothesis}

Traditional morphologic-based studies recognize three families of Choanoflagellata (Leadbeater 1983), according to whether the cells are naked (Codonosigidae), covered with a theca (Salpingoecidae) or surrounded by a siliceous lorica (Acanthoecidae). Of the 12 genera in Acanthoecidae; we have sequences for species in three of them (Acanthocoepsis, Diaphanoeca and Stephanoeca). These three species form a robustly supported clade (Fig. 1), suggesting that these species share a lorica because they had a lorica-bearing ancestor. The possession of a theca, however, does not appear to have phylogenetic significance at the level of this analysis. The two thecate species sampled (Salpingoeca infusionum and Choanoeca perplexa) are in separate clades, and may possess this character through convergence. This result is not surprising, for example, Leadbeater (1983) noted that one species of naked choanoflagellate (the colonial Proterosponga choanojuncta) contains a phase in its life cycle that is indistinguishable from that in a theca-bearing species (the sedentary unicellular Choanoeca perplexa). Our SSU sequences of these two species are identical, indicating that they are either very closely related or they are different stages in the life cycle of a single species, as implied by Leadbeater's observations. Finally, an available SSU sequence, recovered from an environmental sample of picoplankton (Moon-van der Staay et al. 2001), appears to represent a phantom choanoflagellate that is more closely related to Salpinoeca infusionum than to any other sampled species. Cavalier-Smith (1987) proposed that two different lineages of choanoflagellates 


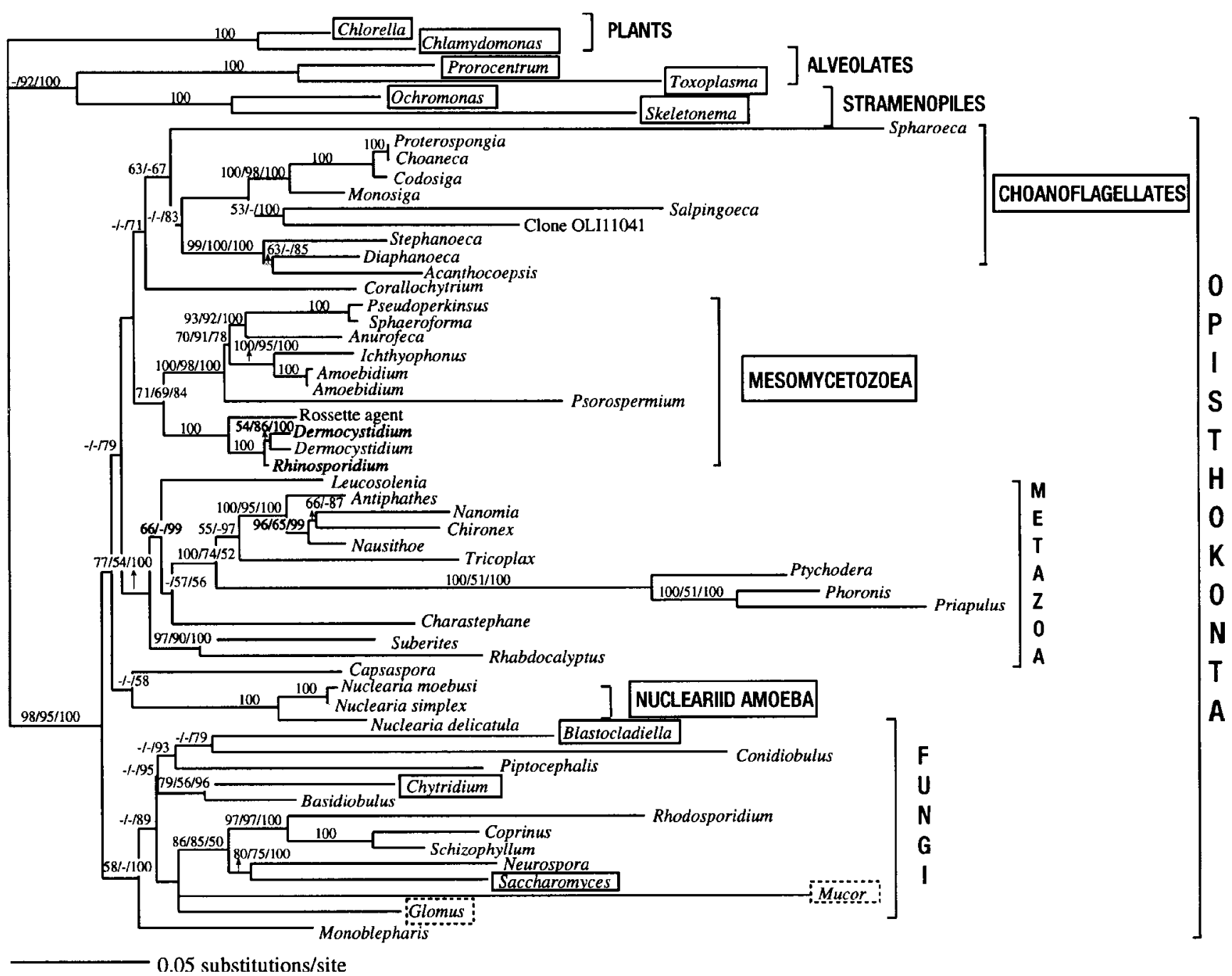

Fig. 2. Opisthokont phylogenetic analysis of SSU rDNA. Best tree obtained by ML. The first two values above branches correspond to bootstrap values for MP and ME respectively. The third value corresponds to posterior probabilities from the Bayesian analysis (a single value of 100 indicates same support in all analyses). Unicellular organisms are boxed. Evolutionary distance is represented by the scale bar. See Table 2 for complete species names. * Mucor can grow as a yeast and Icthyophonus makes filaments and sporangia.

independently gave rise to animals and Fungi. He suggested that a codosigid choanoflagellate gave rise to animals, whereas Fungi could have evolved from a salpingoecid choanoflagellate. This hypothesis is contradicted by our molecular evidence. Codonosigid (e.g. Monosiga brevicolis) and salpingoecid (e.g. Salpingoeca infusionum) lineages are included in a well-supported clade distinct from either Fungi or animals in both the combined and SSU analyses. Nevertheless, extinct stem group choanoflagellates are not precluded as the ancestors of Metazoa.

\section{Overall opisthokont phylogeny and character evolution}

The relations among a constellation of rather disparate groups within the Opisthokonta have not been clarified by the SSU gene. In addition to the nuclear ribosomal genes, nuclear and mitochondrial protein coding genes studied in some opisthokont taxa (Baldauf \& Palmer 1993; Baldauf \& Doolittle 1997; King \& Carroll 2001; Snell et al. 2001; Lang et al. 2002) supported a close phylogenetic relationship between animals and Fungi to the exclusion of plants, although only a few studies included any of the opisthokont protists (King \& Carroll 2001; Snell et al. 2001; Lang et al. 2002). Data from the protein coding genes EF-2, $\alpha$ and $\beta$-tubulins, and actin (King \& Carroll 2001) as well as from the hsp70 gene (Snell et al. 2001) indicated that choanoflagellates are part of the opisthokont clade, and possibly the sister group to animals. King \& Carroll (2001) also reported a receptor tyrosine kinase (RTK), similar to the metazoan RTKs, which are widely involved in developmental pathways. Whether or not other opisthokont protistan lineages also have RTKs is unkown. A comprehensive analysis (Lang et al. 2002) of 11 conserved mitochondrial proteins from many protests, including both a choanoflagellate 
Table 2. List of species, current taxonomic classification and accession numbers for the SSU analysis; new sequences are presented in bold

\begin{tabular}{|c|c|c|}
\hline & & $\begin{array}{l}\text { SSU } \\
\text { Access. No. }\end{array}$ \\
\hline \multicolumn{3}{|l|}{ Outgroup taxa } \\
\hline Chlorella lobophora & Viridiplantae & X63504 \\
\hline Chlamydomonas reinhardtii & Viridiplantae & M32703 \\
\hline Prorocentrum minimum & Alveolate & Y16238 \\
\hline Toxoplasma gondii & Alveolate & L37415 \\
\hline Ochromonas CCMP584 & Stramenopile & U42381 \\
\hline Skeletonema pseudocostatum & Stramenopile & X85393 \\
\hline \multicolumn{3}{|l|}{ Choanoflagellates } \\
\hline Sphaeroeca volvox & Codonosigidae & Z34900 \\
\hline $\begin{array}{l}\text { Proterospongia choanojuncta } \\
\text { ATCC } 50455\end{array}$ & Codonosigidae & AY149896 \\
\hline Codosiga gracilis ATCC 50454 & Codonosigidae & AY149897 \\
\hline Monosiga brevicolis ATCC 50154 & Codonosigidae & AF 100940 \\
\hline Choanoeca perplexa ATCC 50453 & Salpingoecidae & AY149898 \\
\hline $\begin{array}{l}\text { Salpingoeca infusorium } \\
\text { ATCC } 50559\end{array}$ & Salpingoecidae & AF100941 \\
\hline $\begin{array}{l}\text { Stephanoeca diplocostata } \\
\text { ATCC } 50456\end{array}$ & Acanthoecidae & AY149899 \\
\hline Diaphanoeca grandis ATCC 50111 & Acanthoecidae & L10824 \\
\hline $\begin{array}{l}\text { Acanthoecopsis ungiculata } \\
\text { ATCC } 50073\end{array}$ & Acanthoecidae & L10823 \\
\hline Eukaryote clone OLI11041 & & AJ402325 \\
\hline \multicolumn{3}{|l|}{ Opisthokont inserta sedis } \\
\hline Corallochytrium limacisporum & & L42528 \\
\hline \multicolumn{3}{|l|}{ Mesomycetozoea } \\
\hline Pseudoperkinsus tapetis & Dermocystida & AF192386 \\
\hline $\begin{array}{l}\text { Rossette agent of } \\
\text { Chinook salmon }\end{array}$ & Dermocystida & L29455 \\
\hline Dermocystidium salmonis & Dermocystida & U21337 \\
\hline Dermocystidium sp. & Dermocystida & U21336 \\
\hline Rhinosporidium seeberi & Dermocystida & AF118851 \\
\hline Amoebidium parasiticum & Ichthyphonida & AF274751 \\
\hline Amoebidium parasiticum & Ichthyphonida & Y19155 \\
\hline Ichthyophonus hoferi & Ichthyphonida & U25637 \\
\hline Psorospermium haeckelii & Ichthyphonida & U33180 \\
\hline Anurofeca richardsi & Ichthyphonida & AF070445 \\
\hline Sphaeroforma artica & Ichthyphonida & Y16260 \\
\hline $\begin{array}{l}\text { *Capsaspora owczarzaki } \\
\text { ATCC } 30864\end{array}$ & & AF349564 \\
\hline \multicolumn{3}{|l|}{ Animals } \\
\hline Leucosolenia sp. & Porifera & AF100945 \\
\hline Suberites ficus & Porifera & AF 100947 \\
\hline Rhabdocalyptus dawsoni & Porifera & AF100949 \\
\hline Antiphathes galapagensis & Cnidaria & AF100943 \\
\hline Nanomia bijuga & Cnidaria & AF358071 \\
\hline Chironex fleckeri & Cnidaria & AF358104 \\
\hline Nausithoe rubra & Cnidaria & AF358095 \\
\hline Trichoplax adherens & Placozoa & L10828 \\
\hline Charistephane fugiens & Ctenophora & AF358113 \\
\hline Ptychodera bahamensis & Hemichordata & AF236802 \\
\hline Phoronis hippocrepia & Phoronida & AF202112 \\
\hline Priapulus caudatus & Sipuncula & AF025927 \\
\hline \multicolumn{3}{|l|}{ Fungi } \\
\hline Saccharomyces cerevisiae & Ascomycota & M27607 \\
\hline Neurospora crassa & Ascomycota & X04971 \\
\hline Basidiobulus ranarum & Zygomycota & D29946 \\
\hline Conidiobulus coronatus & Zygomycota & D29947 \\
\hline Piptocephalis corymbifera & Zygomycota & AB016023 \\
\hline Mucor mucedo & Zygomycota & X89434 \\
\hline Glomus mosseae & Zygomycota & Z14007 \\
\hline
\end{tabular}

Table 2 (cont.)

\begin{tabular}{|c|c|c|}
\hline & & $\begin{array}{l}\text { SSU } \\
\text { Access. No. }\end{array}$ \\
\hline Monoblepharis insignis & Chytridiomycota & AF 164333 \\
\hline Blastocladiella emersonii & Chytridiomycota & M54937 \\
\hline Chytridium confervae & Chytridiomycota & M59758 \\
\hline Coprinus cinereus & Basydiomycota & M92991 \\
\hline Schizophyllum commune & Basydiomycota & X54865 \\
\hline Rhodosporidium toruloides & Basydiomycota & D12806 \\
\hline \multicolumn{3}{|l|}{ Nucleariid amoeba } \\
\hline Nuclearia moebiusi CCAP (1552/3) & Nucleariidae & AF349565 \\
\hline Nuclearia simplex CCAP (1552/4) & Nucleariidae & AF349566 \\
\hline Nuclearia delicatula CCAP (1552/1) & Nucleariidae & AF349563 \\
\hline
\end{tabular}

and a mesomycetozoean places these two lineages in a monophyletic assemblage that contains the Metazoa, with the choanoflagellates strongly supported as the sister group to metazoans and the mesomycetozoean as the most basal lineage in this clade. Although our phylogenetic analysis had weak support for some key nodes, overall it is consistent with the mitochondrial data (Lang et al. 2002). Our data therefore add support to the inference that multicellularity evolved twice in the Opisthokonta, once in the animals and again in the Fungi.

Although the morphological evidence is quite indicative and partly in agreement with the molecular data (this study, and Lang et al. 2002), the two synapomorphies used to designate the Opisthokonta (flat mitochondrial cristae and the presence of a posterior flagellum) are labile phylogenetic characters that have reversed to an ancestral state in some lineages. Examples are the presence of tubular mitochondrial cristae in Ichthyophonus hoferi (Ragan et al. 1996) - a mesemycetozoean-and discoidal mitochondrial cristae in the nucleariid amoebae (Amaral-Zettler et al. 2001). Additionally, the nucleariids and the icthyophonid mesomycetozoeans do not produce flagellated cells but amoeba-like cells. Thus, at present there is no clear ultrastructural synapomorphy that is conserved throughout the whole clade. The absence of a universally diagnostic morphological synapomorphy of Opisthokonta is not surprising given the great age and diversity of the clade. We will probably have to rely, therefore, on sequence data and biochemical data (e.g. gene networks) to identify appropriate diagnostic characters for this eukaryotic group. For example, the discovery of a gene fusion between dihydrofolate reductase (DHFR) and thymidylate synthase (TS) in representatives of major eukaryotic lineages to the exclusion of the currently sampled opisthokont taxa (animals, fungi and Corallochytrium limacisporum) offers additional evidence for their monophyly (Stechmann \& Cavalier-Smith 2002). These genes are also separately translated in eubacteria, a fact that was used to place the eukaryotic root between opisthokonts and the rest of the eukaryotic domain (Stechmann \& Cavalier-Smith 2002; Simpson \& Roger 2002). Although the separate DHFR and TS translation represents an ancestral state and the taxon sampling is still limited, this genomic trait exemplifies the type of information that will become 
increasingly valuable in recognizing groups that share common ancestry.

\section{Evolution of complexity in Fungi}

Within the Fungi, simple linear multicellularity of hyphae occurs in all major clades (see below), but only Ascomycota and Basidomycota display more complex two- and threedimensional multicellularity in the form of sexual sporeproducing fruiting bodies. In both of these groups, reversals to unicellular lifeforms have occurred, for example, Saccharomyces and many other related yeasts in the Saccharomycotina (Ascomycota) or Cryptococcus albidus and related species in the hymenomycete clade of Basidiomycota (de Hoog et al. 2000, p. 130). Yeasts in the Taphrinomycotina of the Ascomycota, Schizosaccharomyces sp. and Pneumocystis carinii, may represent reversals to unicellular life, given the presence in that clade of Neolecta sp. with macroscopic, multicellular sexual structures (Landvik et al. 1993).

The single posterior flagellum and strong swimming motility of Blastocladiales, Monoblepharidales and Neocallimastigales zoospores (Sparrow 1960), as well as their amoeboid movement, are features shared with animals, choanoflagellates, Mesomycetozoea, and amoebae, providing a strong argument that the last common ancestor of these groups was aquatic and had these attributes. Together, the Chytridiomycota and Zygomycota account for no more than $2 \%$ of fungal species, raising the possibility that multicellular fruiting bodies were an advantage that allowed Ascomycota and Basidiomycota to become far more numerous. Within Ascomycota and Basidiomycota, not all clades have multicellular fruiting bodies but the clades that do (Pezizomycotina in Ascomycota (and Taphrinomycotina, but only in Neolecta sp.), Hymenomycetes in Basidiomycota) are more speciose than sibling clades lacking multicellular fruiting bodies (Saccharomycotina in Ascomycota, Ustilaginomycetes and Urediniomycetes in Basidiomycota). However, multicellular reproductive structures are large and more likely to be seen by biologists, which probably biases the counting of these organisms, a possibility that could be tested by thorough surveys of biodiversity. In Opisthokonta, the simple, linear multicellularity of hyphae is found in Mesomycetozoea and Fungi, but whether it arose independently in each or was an ancestral character lost in choanoflagellates and Metazoa is unknown. Hyphae of the earliest diverging fungi, Blastocladiales, show differentiation among hyphal segments in the production of mitotic and meiotic sporangia or gametangia, best documented in Allomyces macrogynus (Emerson 1941). However, the multicellularity that allows for more extensive differentiation of function is reserved for sexual fruiting bodies of the Pezizomycotina clade of Ascomycota or the Hymenomycetes clade of Basidiomycota. Here, simple switches that specify the production of a sporangium instead of a vegetative hypha cannot explain the many different tissues of in each of the major organs of a mushroom, instead complex coordination of development by many gene products must be invoked (Wessels \& Meinhardt 1994; Kamada 2002).

\section{Evolution of animal complexity}

The Choanoflagellata lineage has a cell morphology that is closely similar to those in Porifera. The microvillar-flagellar structure of the choanoflagellate collar is unique among protistan opisthokonts, and does not occur in other flagellate groups (Karpov 2000). Only among sponge choanocytes are similar collar cells found. This shared morphological feature suggests a close relationship between choanoflagellates and sponges (e.g. James-Clark 1868; Fjerdingstad 1961; Laval 1971; Leadbeater 1985). Other metazoan cells may have collar-like structures, but they do not closely resemble choanoflagellate cells. The collars are used similarly in feeding in both choanoflagellates and sponges, and hence there are functional as well as morphological resemblances. Flagellar activity creates a current flowing away from the cell apex, thus drawing water and suspended food items to the collar, where particles can be trapped and ingested. The homology of the choanoflagellate cell with sponge choanocytes is compatible with the ribosomal DNA phylogenies and strongly agrees with the mitochondrial data (Lang et al. 2002).

In contrast to choanoflagellates, crown mesomycetozoeans make poor models for metazoan ancestors. If mesomycetozoeans are more basal within Opisthokonta than are choanoflagellates, then stem mesomycetozoeans probably included free-living, flagellated forms from which both their crown groups and the crown choanoflagellates have descended, following very divergent modes of life.

The adaptive pathway that led from choanoflagellates to the multicellular sponges may have involved the organization of different cell types. Choanoflagellate cells, with only a single microtubule organizing centre, cannot bear a flagellum and generate a spindle at the same time (Margulis 1981). In order to divide, the cells must resorb the flagellum. There are thus two morphological cell phases, one for dividing cells and one for 'adult' cells. In colonial choanoflagellates, both cell phases may be present within the colony at the same time and the phases may be patterned, in some cases with dividing cells inside a layer of flagellar cells. Buss (1987) suggested that these cell phases foreshadowed differentiated cell types that evolved within early metazoans.

A plausible pathway for a colonial choanoflagellate to become truly multicellular is for one of the cell phases to become a stem cell, reproducing itself as well as giving rise to the other cell morphology. The morphologically distinct cells are then differentiated cell types. As the morphologies of both phases are encoded within the choanoflagellate genome, the change from cell phase to cell type must involve, capturing from environmental or physiologic cues the regulatory signals that mediate the different cytoarchitectures, and embedding them in a developmental repertoire (Valentine, in press). Such a capture is tantamount to establishing the sort of developmental process that is associated with multicellularity. The co-opting of genes and of developmental pathways has clearly occurred between major taxa, such as phyla and classes, by cis-regulatory evolution 
(e.g. Lowe \& Wray 1997 for echinoderms, Akam et al. 1988 for arthropods, and see Carroll et al. 2001; Wilkins 2002). A variety of detailed mechanisms could be responsible for such gene recruitment, and at present no evidence indicates what precisely might have happened during the postulated choanoflagellate-sponge transition. In view of subsequent evolutionary events within Metazoa, homeobox genes may be involved.

\section{Conclusions}

Multicellularity might be an adaptive strategy for increased body size (e.g. Cox \& Bonner 2001). Certainly, multicellularity is homoplastic among many clades, perhaps as many as 24 (Buss 1987). However, the major multicellular kingdoms belong to a clade that includes Opisthokonta and Chlorobiota, and innovations in molecular mechanisms may have permitted the rise of true multicellularity in complex body plans (see Stiller \& Hall 2002). Reductions in size and complexity within multicellular clades are also well known. The unicellular state exemplified by some Fungi that have close multicellular relatives (e.g. Saccharomyces) can most easily be interpreted as a secondary simplification. Simplifications, though not completely reverting to a singlecelled state, may also account for the simple body plans found in several metazoan groups, usually parasites (e.g. Myxozoa, Orthonecta, Rhombozoa and the somewhat more complex Nematomorpha).

As new genomes are being completed for diverse members of the opisthokont clade, a comparative approach will be essential to address these questions. Comparative studies of the developmental and physiological processes that lead to multicellularity, as well as those that lead to reduced numbers of cell types, will thus provide insights into the evolution of both complexity and simplicity. Information on gene regulation throughout ontogeny is rapidly accumulating and is being synthesized (see Carroll et al. 2001; Davidson 2001; Wilkins 2002). It will be of great interest to learn what are the unique features that characterize Opisthokonta and that were implicated in the evolution of the numerous complexity increases found within that clade.

\section{Acknowledgments}

We are grateful to J. Silberman for helpful comments on different aspects of opisthokont evolution and phylogenetics. This research was supported by NIH grant GM32964, by NSF grant EAR-9814845, and by the NASA Astrobiology Institute, membership NCC2-1054. JT was supported by NSF Systematic Biology and NIH NIAID grants. Part of this work was performed under the auspices of the US Department of Energy, Office of Biological and Environmental Research, by the University of California, Lawrence Berkeley National Laboratory under contract no DE-AC0376SF00098. This is UC Berkeley Museum of Paleontology contribution number 1804 .

\section{References}

Akam, M., Dawson, I. \& Tear, G. (1988). Homeotic genes and the control of segment diversity. Development 104 (Suppl.), 123-144.

Amaral-Zettler, L.A., Nerad, T.A., O'Kelly, C.J. \& Sogin, M.L. (2001). The nucleariid amoebae: more protists at the animal-fungal boundary. J. Euk. Microbiol. 48, 293-297.

Atkins, M.S., McArthur, A.G. \& Teske, A.P. (2000). Ancyromonadida: a new phylogenetic lineage among the protozoa closely related to the common ancestor of metazoans, fungi and choanoflagellates (Opisthokonta). J. Mol. Evol. 51, 278-285.

Baldauf, S.L. \& Doolittle, W.F. (1997). Origin and evolution of the slime molds. Proc. Natl Acad. Sci., USA 94, $12007-12012$.

Baldauf, S.L. \& Palmer, J.D. (1993). Animals and fungi are each others closest relatives: congruent evidence from multiple proteins. Proc. Natl Acad. Sci., USA 90, $11558-11562$.

Buss, L.W. (1987). The Evolution of Individuality, p. 201. Princeton University Press, Princeton.

Carroll, S.B., Grenier, J.K. \& Weatherbee, S.D. (2001). From DNA to Diversity: Molecular Genetics and the Evolution of Animal Design, p. 214. Blackwell, Malden.

Cavalier-Smith, T. (1987). In Evolutionary Biology of the Fungi, eds Rayner, A.D.M., Brasier, C.M. \& Moore, D.M., pp. 339-353. Cambridge University Press, Cambridge.

Cavalier-Smith, T. (1998). In Evolutionary Relationships among Protozoa, eds Coombs, G.H., Vickerman, K., Sleigh, M.A. \& Warren, A., pp. 375-407. Kluwer, Dordrecht.

Cavalier-Smith, T. (2000). The Flagellates, eds. Leadbeater, B.S.C. \& Green, J.C., pp. 361-390. Taylor \& Francis, London.

Cavalier-Smith, T. \& Allsopp, M.T.E.P. (1996). Corallochytrium, an enigmatic non-flagellate protozoan related to choanoflagellates. Eur. J. Protist. 32, 1-9.

Chomczynski, P., Mackey, K., Drews, R. \& Wilfinger, W. (1997). DNAzol: a reagent for the rapid isolation of genomic DNA. BioTechniques 22, 550-553.

Collins, A.G. (1998). Evaluating multiple alternative hypotheses for the origin of Bilateria: an analysis of $18 \mathrm{~S}$ rRNA molecular evidence. Proc. Natl Acad. Sci., USA 95, 15458-15463.

Cox, E.C. \& Bonner, J.T. (2001). The advantages of togetherness. Science 292, 448-449.

Davidson, E.H. (2001). Genomic Regulatory Systems: Development and Evolution, p. 261. Academic Press, San Diego, CA.

De Hoog, G.S., Guarro, J., Gené, J. \& Figueras, M.J. (2000). Atlas of Clinical Fungi, 2nd edn, p. 1126. Cbs, Utrecht, Netherlands and Universitat Roviera, Reus, Spain.

Emerson, R. (1941). An experimental study of the life cycle and taxonomy of Allomyces. Lloydia 4, 77-144.

Fjerdingstad, E.J. (1961). Ultrastructure of the collar of the choanocyte collars in Spongilla lacustris (L.). Z. Zeliforsch. 53, 645-647.

Herr, R.A., Ajello, L., Taylor, J.W., Arseculeratne, S.N. \& Mendoza, L. (1999). Phylogenetic Analysis of Rhinosporidium seeberi's $18 \mathrm{~S}$ Small-Subunit Ribosomal DNA groups this pathogen among members of the protoctistan Mesomycetozoa clade. J. Clin. Microbiol. 37, 2750-2754.

Hertel, L.A., Bayne, C.J. \& Loker, E.S. (2002). The symbiont Capsaspora owczarzaki, nov. gen. nov. sp., isolated from three strains of the pulmonate snail Biomphalaria glabrata is related to members of the Mesomycetozoea. Int. J. Parasitol. 32, 1183-1191.

Huelsenbeck, J.P. \& Ronquist, F. (2001). MrBAYES: Bayesian inference of phylogenetic trees. Bioinformatics 17, 754-755.

James-Clark, H. (1868). On the Spongiae Ciliatae as Infusoria Flagellata; or observations on the structure, animality, and relationship of Leucosolenia botryoides, Bowerbank. Ann. Mag. Nat. Hist. 1, 133-142, 188-215, 250-264.

James, T.Y., Porter, D., Leander, C.A., Vilgalys, R. \& Longcore, J.E. (2000). Molecular phylogenetics of the Chytridiomycota supports the utility of ultrastructural data in chytrid systematics. Can. J. Botany V78(N3), 336-350. 
Kamada, T. (2002). Molecular genetics of sexual development in the mushroom Coprinus cinereus. BioEssays 24, 449-459.

Karpov, S.A. (2000). In The Flagellates, eds Leadbeater, B.S.C. \& Green, J.C., pp. 336-360. Taylor \& Francis, London.

King, N. \& Carroll, S.B. (2001). A receptor tyrosine kinase from choanoflagellates: molecular insights into early animal evolution. Proc. Natl Acad. Sci., USA 98, 15032-15037.

Landvik, S., Eriksson, O.E., Gargas, A. \& Gustafsson, P. (1993). Relationships of the genus Neolecta (Neolectales ordo nov., Ascomycotina) inferred from 18S rDNA sequences. Systema Ascomycetum 11, 107-118.

Lang, B.F., O'Kelly, C.O., Nerad, T., Gray, M.W. \& Burger, G. (2002). The closest unicellular relatives of animals. Cur. Biol. 12, 1772-1778.

Laval, M. (1971). Ultrastructure et mode de nutrition du choanoflagelle Salpingoeca pelagica, sp. nov. comparaison avec les choanocytes des spongiares. Prototistologica 7, 325-336.

Leadbeater, B.S.C. (1983). Life-history and ultrastructure of a new marine species of Proterospongia (Choanoflagellida). J. Mar. Biol. Ass. UK 63, 135-160.

Leadbeater, B.S.C. (1985). In Illustrated Guide to the Protozoa, eds Lee, J.J., Hutner, S.H. \& Bovee, E.C., pp. 106-116. Allen Press, Lawrence.

Lowe, C.J. \& Wray, G.A. (1997). Radical alterations in the roles of homeobox genes during echinoderm evolution. Nature 389, 718-721.

Margulis, L. (1981). Symbiosis in Cell Evolution, p. 419. Freeman, San Francisco, CA.

Medina, M., Collins, A.G., Silberman, J.D. \& Sogin, M.L. (2001). Evaluating hypotheses of basal animal phylogeny using complete sequences of large and small subunit rRNA. Proc. Natl Acad. Sci., USA 98, 9707-9712.

Medlin, L., Elwood, H.J., Stickel, S. \& Sogin, M.L. (1988). The characterization of enzymatically amplified eukaryotic 16S-like rRNA-coding regions. Gene 71, 491-499.

Mendoza, L., Ajello, L. \& Taylor, J.W. (2001). The taxonomic status of Lacazia loboi and Rhinosporidium seeberi has been finally resolved with the use of molecular tools. Rev. Iberoam. Micol. 18, 95-98.

Mendoza, L., Taylor, J.W. \& Ajello, L. (2002). The class Mesomycetozoea: a heterogenous group of microorganisms at the animal-fungal boundary. Ann. Rev. Microbiol. 56, 315-344.
Moon-van der Staay, S.Y., De Wachter, R. \& Vaulot, D. (2001). Oceanic $18 \mathrm{~S}$ rDNA sequences from picoplankton reveal unsuspected eukaryotic diversity. Nature 409, 607-610.

Nagahama, T., Sato, H., Shimazu, M. \& Sugiyama, J. (1995) Phylogenetic divergence of the entomophthoralean fungi: evidence from nuclear $18 \mathrm{~S}$ ribosomal RNA gene sequences. Mycologia 87, 203-209.

Nielsen, C. (2001). Animal Evolution. Oxford University Press, New York.

Posada, D. \& Crandall, K.A. (1998). MODELTEST: testing the model of DNA substitution. Bioinformatics 14, 817-818.

Ragan, M.A., Goggin, C.L., Cawthorn, R.J., Cerenius, L., Jamieson, A.V.C., Plourde, S.M., Rand, T.G., Soderhall, K. \& Gutell, R.R. (1996). A novel clade of protistan parasites near the animal-fungal divergence. Proc. Natl Acad. Sci., USA 93, 11907-11912.

Simpson, A.G. \& Roger, A.J. (2002). Eukaryotic evolution: getting to the root of the problem. Curr. Biol. 12, R691-R693.

Snell, E.A., Furlong, R.F. \& Holland, P.W.H. (2001). Hsp70 sequences indicate that choanoflagellates are closely related to animals. Cur. Biol 11, 967-970.

Sparrow, F.K. Jr. (1960). Aquatic Phycomycetes, 2nd edn, p. 1187. University of Michigan Press, Ann Arbor, MI.

Stechmann, A. \& Cavalier-Smith, T. (2002). Rooting the Eukaryote tree by using a derived gene fusion. Science 297, 89-91.

Stiller, J.W. \& Hall, B.D. (2002). Evolution of the RNA polymerase II C-terminal domain. Proc. Natl Acad. Sci., USA 99, 6091-6096.

Swofford, D.L. (2000). PAUP*. Phylogenetic Analysis Using Parsimony (*and other methods). Version 4. Sinauer Associates, Sunderland.

Valentine, J.W. On the Origin of Phyla. University of Chicago Press, Chicago, IL (in press)

Wainright, P.O., Hinkle, G., Sogin, M.L. \& Stickel, S.K. (1993). Monophyletic origins of the Metazoa: an evolutionary link with fungi. Science 260, 340-342.

Wessels, J.G.H. \& Meinhardt, F. (1994). The Mycota, I; Growth, Differentiation and Sexuality, p. 433. Springer-Verlag, New York.

Wilkins, A. (2002). The Evolution of Developmental Pathways, p. 603 Sinauer Associates, Sunderland. 